\title{
Numerical Simulation of Free Convection in a Three-Dimensional Enclosure Full of Nanofluid with the Existence a Magnetic Field
}

\author{
Said Bouchta*, M'barek Feddaoui \\ LGEMS, Ibn Zohr University, ENSA, Agadir BP 1136, Morocco
}

Corresponding Author Email: saidbouchta.doc@gmail.com

https://doi.org/10.18280/ejee.220602

Received: 3 May 2020

Accepted: 11 November 2020

\section{Keywords:}

three-dimensional, nanofluid, magnetic field, convection, finite volume method, SIMPLEC, Hartmann number, numerical simulation

\begin{abstract}
A numerical analysis was performed to study the influence of a magnetic field in free convection in a cube full with nanofluid. To solve the equation, we appeal to finite volume method. The SIMPLEC algorithm is used for pressure-velocity coupling. All walls are adiabatic, except for the left and right walls that are heated differently. The effects of the Rayleigh and Hartmann numbers, as well as the volume fraction of nanometric particles were studied. Results are conveyed in the form of isotherms, streamlines, velocity curves and Nusselt numbers. It has been shown that as the percentage of nanoparticles increases and the number of Rayleigh increases, heat transfer improves. Hartman number has considerable influence on hydrodynamic and thermal field.
\end{abstract}

\section{INTRODUCTION}

Conventional liquids used in free convection, for example water, ethylene glycol or oil have a limited thermal conductivity, which led to replacing them with a new fluid named by physicists, nanofluid. Nanofluids are colloidal solutions composed of nanoparticles suspended in a base liquid, invented by Choi and Eastman [1]. Nanofluids have an important thermal conductivity and show significant progress in convection [2].

Nanofluids can be used everywhere where large heat flows must be evacuated: heat exchangers, cooling of electrical and electronic components, radars, automobile ...

Many researchers are concentrating their research on nanofluids. Khanafer et al. [3] examined Numerically the free convection of nanofluids. Their results showed that in any Grashof number, nanoparticles added to the base fluid significantly increase the heat transfer rate. Abu-Nada and Oztop [4] have shown that heat transfer is very crucial with increasing of nanoparticles. Oztop and Abu-Nada [5] carried out two dimensions investigation of the free convection of diverse nanofluids in partially heated enclosure, they showed that the genre of nanoparticles was a key essential in improving heat transfer. They obtained the best results using copper nanoparticles.

Other investigators have investigated several nanofluidfilled geometries [6-8], different thermal boundary conditions, [9-11], and different internal shapes [12, 13] for improvement and intensification of heat exchange.

Free convection in 3D cavities fulled of nanofluid has been addressed by few researchers, such as Ravnik et al. [14] analyzed free convection in a cube fulled with nanofluids using the Border Element Method (BEM). El Moutaouakil et al. [15] was investigates the effect of thermal radiation on natural convection of various nanofluids in a partially heated cubical cavity. They studied the effect on the dynamic and thermal fields as well as the heat transfer of several parameters, the volume fraction, the radiation parameter, the aspect ratio of the heated elements, and the angle of inclination of these elements $\left(0^{\circ}, 45^{\circ}\right.$ and $\left.90^{\circ}\right)$. Selimefendigil and Oztop [16] treated heat transfer by convection of carbon nanotube/water nanofluids in 3D cavity separated by a conductive partition and having an internal rotating adiabatic circular cylinder. They analyzed the influence on the heat transfer of various parameters, Richardson number, the angular rotation velocity of the inner cylinder, the thickness and the solid fraction $\varphi$.

Atashafrooz [17] studied numerically in 3D, the circulation of nanofluid in an inclined step. He showed that the nanoparticle volume fraction acts more on the temperature distribution than on the velocity distribution, and increases the coefficient of friction, temperature and Nusselt number.

A three-dimensional simulation of the mesoscopic scale of natural magnetohydrodynamic convection using the Lattice Boltzmann method has been examined by Sajjadi et al. [18]. The findings show that increasing the Hartmann number considerably weakens the heat transfer. In addition, the influence of the $\mathrm{Ha}$ increases with the improvement of the Grashof number, such as the reduction of the average number of Nusselt. Zhou et al. [19] Also used the method Boltzmann, they established a three-dimensional model to analyzing the flow dynamics and heat transfer of mixed convection of $\mathrm{Al}_{2} \mathrm{O}_{3}$ fluid in a three-dimensional cavity in the presence of a magnetic field. Different parameters were taken into consideration in this study of the flow of nanofluids and heat transfer such as Rayleigh, Hartmann and Richardson numbers, nanoparticle volume fraction. The conclusions show that a low $\mathrm{Ra}$, the addition of particles to water can improve heat transfer effect. However, at high Rayleigh numbers, this improvement in heat transfer may weaken or even reverse. In addition, the conclusions show that the applied outside magnetic field has the influence of disappearing the convection state of heat transfer in the enclosure.

Al-Sayegh [20] has numerically analyzed the free convection of a carbon nanotube (CNT)-nanofluid within an 
open trapezoidal enclosure under action of an inclination of the outside magnetic field by the finite volume method. The analysis took into account several factors, note the Rayleigh and Hartmann numbers, the solid fraction, and the angle of inclination of the magnetic force. It has been found that, for high values of $R a$, the heat transfer rate decreases when Hartmann number is increased, while this heat transfer rate improves with increasing volume fraction of the nanoparticles regardless of the angle of inclination of magnetic field.

A numerical analysis of the natural convection of CNT nanofluids, based on finite volumes is carried by Al-Rashed et al. [21], they analyzed the influence of adequate factors, such as the Rayleigh number, the nanoparticles volume fraction, angle of inclination of the outer magnetic field and the Hartman number. They show that heat transfer improves with the addition of CNT particles and Rayleigh number. When $\mathrm{Ha}$ goes from 50 to 100, magnetic repulsion inhibits heat transfer by $50 \%$.

The objective of this work is to study the flow of a nanofluid $(\mathrm{Cu} /$ water) passing through a cube subjected to a magnetic field, as well as to quantify convective exchanges. The effects of nanofluid, the magnetic field as well as the influence of the nanoparticle concentration on the thermal performance of the cavity, are analyzed in this study.

\section{MATHEMATICAL MODELLING}

The study geometry (Figure 1) is a three-dimensional enclosure which is full with and Copper nanoparticles with $P r=6.2$ and heated differently $(T h>T c)$. The other walls are assumed adiabatic. It is subjected to the influence of a constant and uniform outer magnetic field in the horizontal direction.

For the modeling of the physical problem described in Figure 1, we will adopt the following simplifying hypotheses: the flow is laminar, and the fluid is incompressible and Newtonian. Apart from the density that evolves according to the Boussinesq approximation of Bejan [22], all thermophysical properties (at $300 \mathrm{~K}$ ) listed in Table 1, are considered constant.

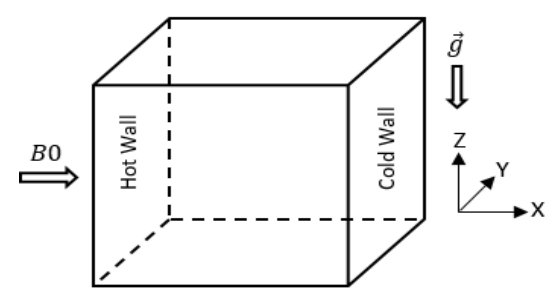

Figure 1. Cavity geometry

Table 1. Thermophysical properties of nanofluid with $\mathrm{T}=300 \mathrm{~K}[5]$

\begin{tabular}{ccc}
\hline Thermophysical properties & Water & $\boldsymbol{C u}$ \\
\hline $\mathrm{cp}\left(\mathrm{J} \mathrm{kg}^{-1} \mathrm{~K}^{-1}\right)$ & 4179 & 385 \\
$\rho\left(\mathrm{kg} \mathrm{m}^{-3}\right)$ & 997.1 & 8933 \\
$\mathrm{k}\left(\mathrm{W} \mathrm{m}^{-1} \mathrm{~K}^{-1}\right)$ & 0.613 & 401 \\
$\beta\left(\mathrm{K}^{-1}\right)$ & $2.761 \times 10^{-4}$ & $1.67 \times 10^{-5}$ \\
$\alpha\left(\mathrm{m}^{2} \mathrm{~s}^{-1}\right)$ & $1.47 \times 10^{-7}$ & - \\
$\sigma(\mu \mathrm{s} / \mathrm{cm})$ & 0.05 & $5.96 \times 10^{7}$ \\
\hline
\end{tabular}

Our system of equations, in steady state, of conservation of mass, conservation of momentum and energy that governs the configuration studied in its dimensionless form is given by:

$$
\begin{gathered}
\frac{\partial U}{\partial X}+\frac{\partial V}{\partial Y}+\frac{\partial W}{\partial Z}=0 \\
U\left(\frac{\partial U}{\partial X}\right)+V\left(\frac{\partial U}{\partial Y}\right)+W\left(\frac{\partial U}{\partial Z}\right) \\
=-\frac{\partial P}{\partial X}+\frac{\mu_{n f}}{\rho_{n f} \alpha_{f}}\left(\frac{\partial^{2} U}{\partial X^{2}}+\frac{\partial^{2} U}{\partial Y^{2}}+\frac{\partial^{2} U}{\partial Z^{2}}\right) \\
U\left(\frac{\partial V}{\partial X}\right)+V\left(\frac{\partial V}{\partial Y}\right)+W\left(\frac{\partial V}{\partial Z}\right) \\
=-\frac{\partial P}{\partial Y}+\frac{\mu_{n f}}{\rho_{n f} \alpha_{f}}\left(\frac{\partial^{2} V}{\partial X^{2}}+\frac{\partial^{2} V}{\partial Y^{2}}+\frac{\partial^{2} V}{\partial Z^{2}}\right)-H a^{2} P r V \\
U\left(\frac{\partial W}{\partial X}\right)+V\left(\frac{\partial W}{\partial Y}\right)+W\left(\frac{\partial W}{\partial Z}\right) \\
=-\frac{\partial P}{\partial Z}+\frac{\mu_{n f}}{\rho_{n f} \alpha_{f}}\left(\frac{\partial^{2} W}{\partial X^{2}}+\frac{\partial^{2} W}{\partial Y^{2}}+\frac{\partial^{2} W}{\partial Z^{2}}\right) \\
+\frac{(\rho \beta)_{n f}}{\rho_{n f} \beta_{f}} \operatorname{Ra} P r \theta-H a^{2} P r W \\
U\left(\frac{\partial \theta}{\partial X}\right)+V\left(\frac{\partial \theta}{\partial Y}\right)+W\left(\frac{\partial \theta}{\partial Z}\right) \\
=\frac{\alpha_{n f}}{\alpha_{f}}\left(\frac{\partial^{2} \theta}{\partial X^{2}}+\frac{\partial^{2} \theta}{\partial Y^{2}}+\frac{\partial^{2} \theta}{\partial Z^{2}}\right)
\end{gathered}
$$

The dimensionless parameters of the previous equations are:

$$
\begin{gathered}
X=\frac{x}{H}, Y=\frac{y}{H}, Z=\frac{z}{H}, U=\frac{u H}{\alpha_{f}}, V=\frac{v H}{\alpha_{f}} W=\frac{w H}{\alpha_{f}}, \\
P=\frac{p H^{2}}{\rho_{n f} \alpha_{f}^{2}}, \theta=\frac{T-T_{C}}{T_{h}-T_{C}} \\
R a=\frac{g \beta_{f}(T h-T c) H^{3}}{\alpha_{f} v_{f}}, \operatorname{Pr}=\frac{v_{f}}{\alpha_{f}}, H a=B_{0} L \sqrt{\frac{\sigma_{n f}}{\rho_{n f} v}}
\end{gathered}
$$

Table 2 shows the thermophysical properties of nanofluid (water- $\mathrm{Cu}$ ).

Table 2. Thermophysical properties of a nanofluid

\begin{tabular}{cc}
\hline Properties & Nanofluid [23] \\
\hline Density & $\rho_{n f}=\left(1-\varphi_{p}\right) \rho_{f}+\varphi \rho_{p}$ \\
Heat capacity & $\left(\rho c_{p}\right)_{n f}=\left(1-\varphi_{p}\right)\left(\rho c_{p}\right)_{f}+\varphi\left(\rho c_{p}\right)_{p}$ \\
$\begin{array}{c}\text { Thermal expansion } \\
\text { coefficient }\end{array}$ & $(\rho \beta)_{n f}=\left(1-\varphi_{p}\right)(\rho \beta)_{f}+\varphi(\rho \beta)_{p}$ \\
Viscosity & $\mu_{n f}=\frac{\mu_{f}}{\left(1-\varphi_{p}\right)^{2.5}}$ \\
Thermal conductivity & $\frac{k_{n f}}{k_{f}}=\frac{k_{p}+2 k_{f}-2 \varphi_{p}\left(k_{f}-k_{p}\right)}{k_{p}+2 k_{f}+\varphi_{p}\left(k_{f}-k_{p}\right)}$ \\
Thermal diffusivity & $\alpha_{n f}=\frac{k_{n f}}{\left(\rho c_{p}\right)_{n f}}$ \\
Electrical conductivity & $\sigma_{n f}=\left(1-\varphi_{p}\right) \sigma_{f}+\varphi \sigma_{p}$ \\
\hline
\end{tabular}

The Eqns. (1)-(5) obtained are solved with the following boundary conditions:

$$
\begin{array}{cc}
U=V=W=0 & \text { on all the walls } \\
\theta=0.5 & \text { with } X=0 \\
\theta=-0.5 & \text { with } X=1 \\
\partial \theta / \partial n=0 & \text { for the others }
\end{array}
$$


where, $\mathrm{n}$ denotes to the normal direction to wall.

The calculation of the average Nusselt number of is based on the following relation:

$$
N u_{a v g}=\int_{0}^{1} \int_{0}^{1}-\frac{k_{n f}}{k_{f}}\left(\frac{\partial \theta}{\partial X}\right)_{X=0} d Z d Y
$$

\section{NUMERICAL METHODE}

We use the finite volume method to discretize the equations of the mathematical model. The obtained equations are solved by the usual iterative method TDMA [24]. The iterative process takes into account the pressure correction by implementing the SIMPLEC algorithm [25], and reaches convergence when the variation of the dependent variables $(\mathrm{U}$, $\mathrm{V}, \mathrm{W}, \mathrm{P}$ or $\theta$ ) is no longer significant. A test for stopping the iterative process at convergence is established at each stretch according to the following criterion:

$$
\sum_{i, j, k=1}^{i \max , j \max , k \max } \frac{\left|\emptyset_{i, j, k}^{n+1}-\emptyset_{i, j, k}^{n}\right|}{\left|\emptyset_{i, j, k}^{n}\right|} \leq 10^{-4}
$$

where, $\varnothing$ is one of the field variables (U, V, W, T, P) and i, j and $\mathrm{k}$ the grid positions. $\mathrm{n}$ represents the time step number.

To verify the numerical program, the results obtained are compared with the results already available in the literature. First comparison is a three-dimensional numerical simulation of free convection of air and water $(P r=0.71)$ at Rayleigh number values ranging from $10^{3}$ to $10^{6}$. Table 3 shows comparisons between our results and those of literature. After consultation, we see that our numerical results are in good coherence with those of reference.

Table 3. Comparison our Nusselt number values with [14]

\begin{tabular}{ccccc}
\hline & \multicolumn{2}{c}{ Air } & \multicolumn{2}{c}{ Water } \\
\cline { 2 - 5 } $\boldsymbol{a}$ & Ravnik et al. & Present & Ravnik et al. & Present \\
& {$[\mathbf{1 4 ]}$} & & 1,071 & \\
\hline $10^{3}$ & 1,071 & 1,0607 & 1.0639 \\
$10^{4}$ & 2,0564 & 2,0464 & 2,078 & 2.0583 \\
$10^{5}$ & 4,3432 & 4,2979 & 4,51 & 4.5237 \\
$10^{6}$ & 8,6792 & 8,6461 & 9,032 & 9.3897 \\
\hline
\end{tabular}

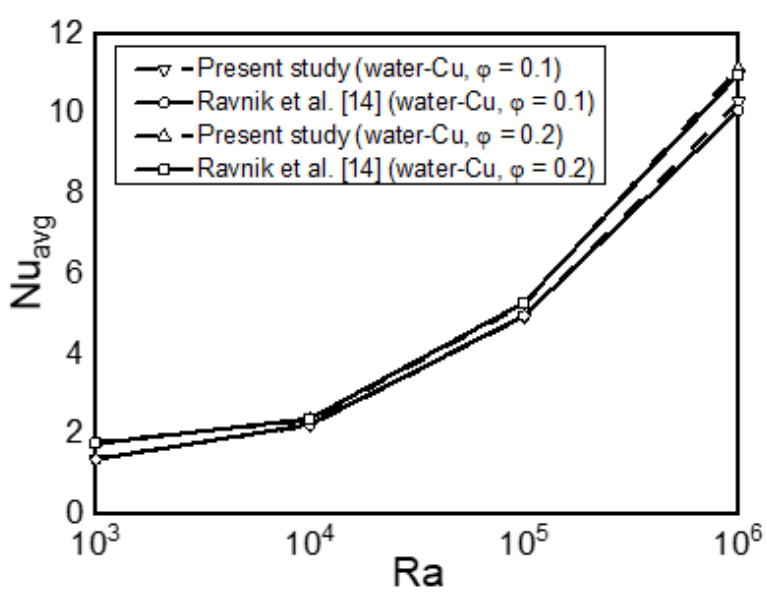

Figure 2. Test of our results of average Nusselt number of with results of Ravnik et al. [14] for $\mathrm{Cu}$-water nanofluid
The second test is still free convection in a threedimensional cavity but with a $C u$-water nanofluid. Our results are compared with those of Ravnik et al. [14] Figure 2 shows that there is a very good agreement between the average number of Nusselt obtained by this simulation and that obtained by Ravnik et al. [14].

\section{RESULTS}

A numerical study was carried by a finite volume method to study the free convection heat transfer and the fluid flow in a cubic cavity exposed to a magnetic field along the $x$ axis, using $\mathrm{Cu}$-water nanofluid. Isotherms, streamlines, velocity profile and variation of average Nusselt number are exposed for different values of $R a\left(10^{3} \ldots 10^{7}, H a(0 \ldots 200)\right.$, and $\varphi(0 \ldots 0.05)$.

Figures 3 and 4 show effect of magnetic field on temperature distribution and fluid flow in cubic enclosure for two values of $R a, \varphi$ and $H a$.

At $R a=10^{5}$, as shown in Figure 3, the circulating flows entrained by the buoyancy force in the enclosure are horizontal. Hartman number increases the cells are elongated vertically and tighten upper streamlines. When the $R a$ is increased from $10^{5}$ to $10^{7}$, the strength of the circulating flows also increases, and decreases when the $\mathrm{Ha}$ increases from 0 to 200. It should be noted that for a high $\mathrm{Ha}$, the velocity field is suppressed considerably and the conduction is dominant. As Rayleigh number increases $R a=10^{7}$, as shown in Figure 3, the convection-dominated regime is strengthened, and still remains despite the Hartman number increase. Due to the delaying influence of the Lorenz force generated by the magnetic field imposed on the enclosure, the intensity of the convection force has decreased considerably. The maximum stream function values indicate the reverse effect of the magnetic field.

In Figure 4, at a Rayleigh number $10^{5}$, for low value of Hartmann number, convection is still dominant, but as $\mathrm{Ha}$ increases, the horizontal isotherms transformed parallel and get more and more to the conduction distribution model. For $R a=10^{7}$, buoyancy force becomes greater and velocity increases, the isotherms also deform since we are in the convection mode which increases the velocity of the flow. We clearly see in Figure 4 that for Rayleigh number $10^{7}$, the convection regime remains dominant even for a high Hartmann number.

The results of the pure fluid (water, $\varphi=0$ ) are also presented in the same Figures 3 and 4 to make comparisons and highlight the effect of the addition of nanoparticles on the dynamic and thermal field. From the values of the current function shown in Figure 3, the flow of pure fluid is stronger than that of nanofluid in the presence of the magnetic field $(\mathrm{Ha}>0)$ while in the absence of the magnetic field $(\mathrm{Ha}=0)$, the trend is reversed and the flow of the nanofluid is more intense than that of the pure fluid. This behavior is due to viscosity and Archimedes' strength which depends on density, and both of these factors are important for nanofluids.

Figure 5 shows velocity distribution $\mathrm{U}$ at $\mathrm{Y}=\mathrm{X}=0.5$ and $\varphi=5 \%$ for $R a=10^{5}$ and $R a=10^{7}$ as function of $Z$ for two values of $H a$. We see the significant decrease in velocity due to the Lorenz force effect when the Hartmann number increases. Whatever value of $\mathrm{Ha}$, the velocity increases from zero near the side wall to a maximum value located in the viscous undercoat. In the heart of the cube, the velocity profile becomes more and more linear for high Hartmann number. The influence of the magnetic field is weaker for $R a=10^{5}$ than $R a=10^{7}$. 


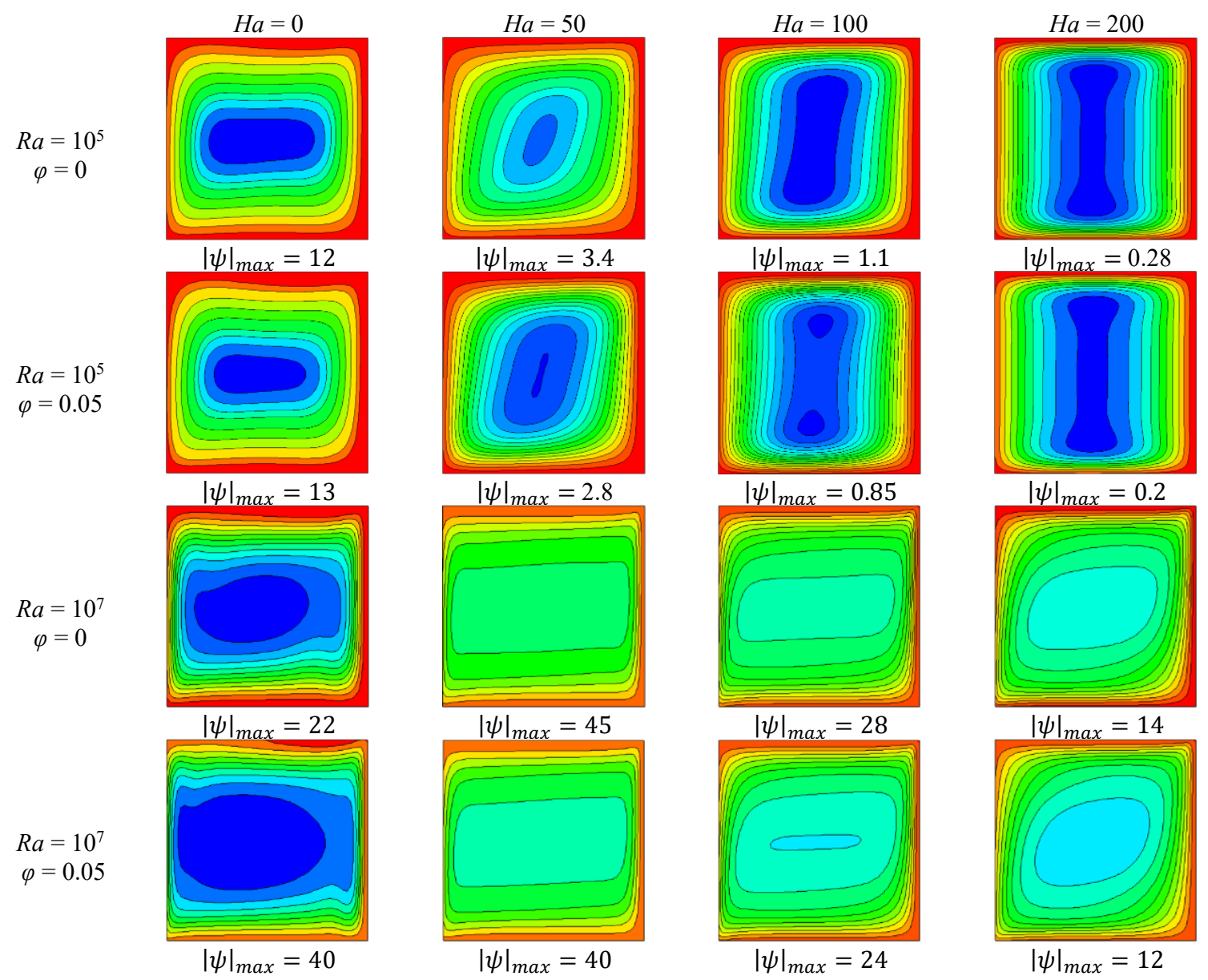

Figure 3. Streamlines for different values of $R a, H a$ and $\varphi$

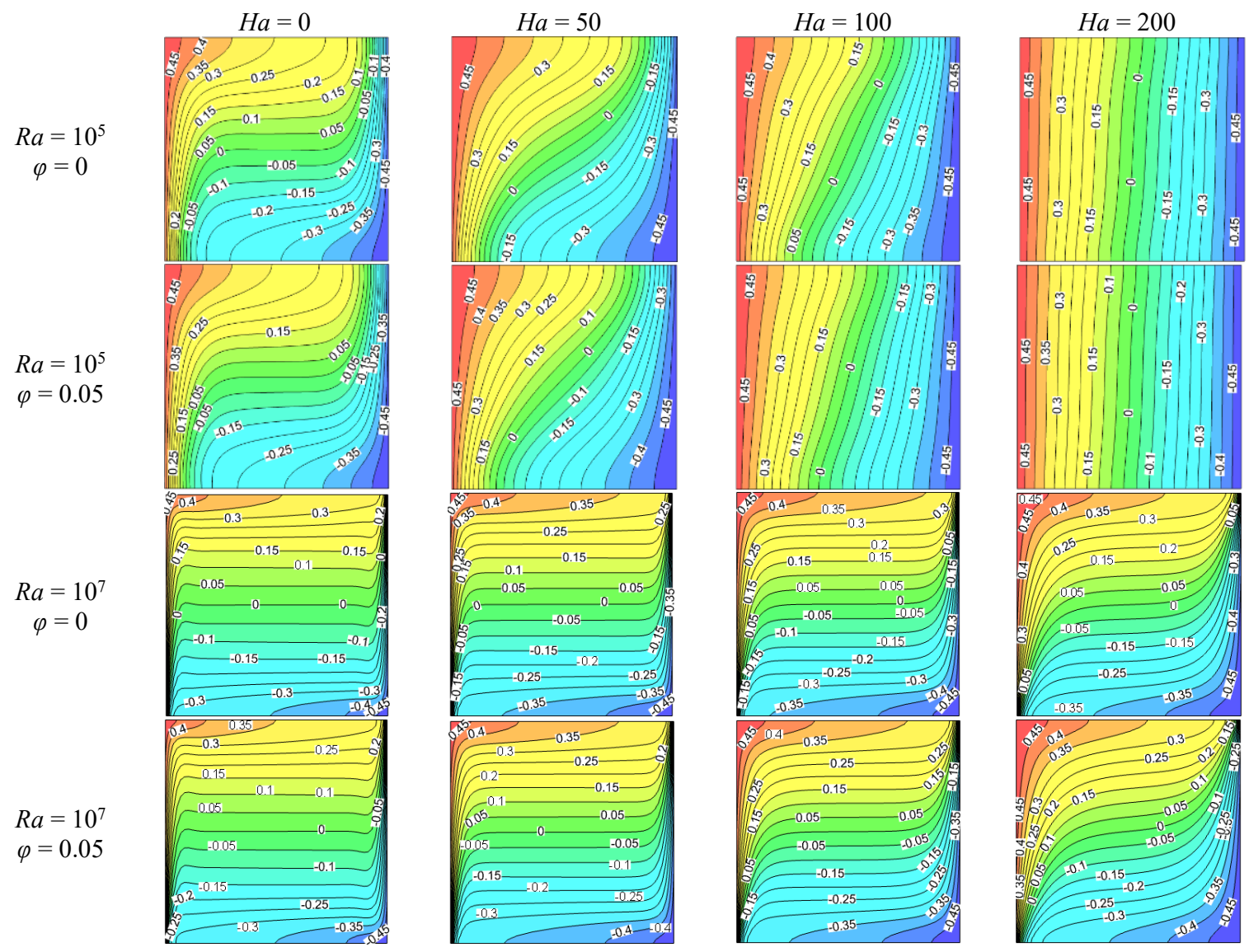

Figure 4. Isothermal lines for different values of $\mathrm{Ra}, \mathrm{Ha}$ and $\varphi$ 

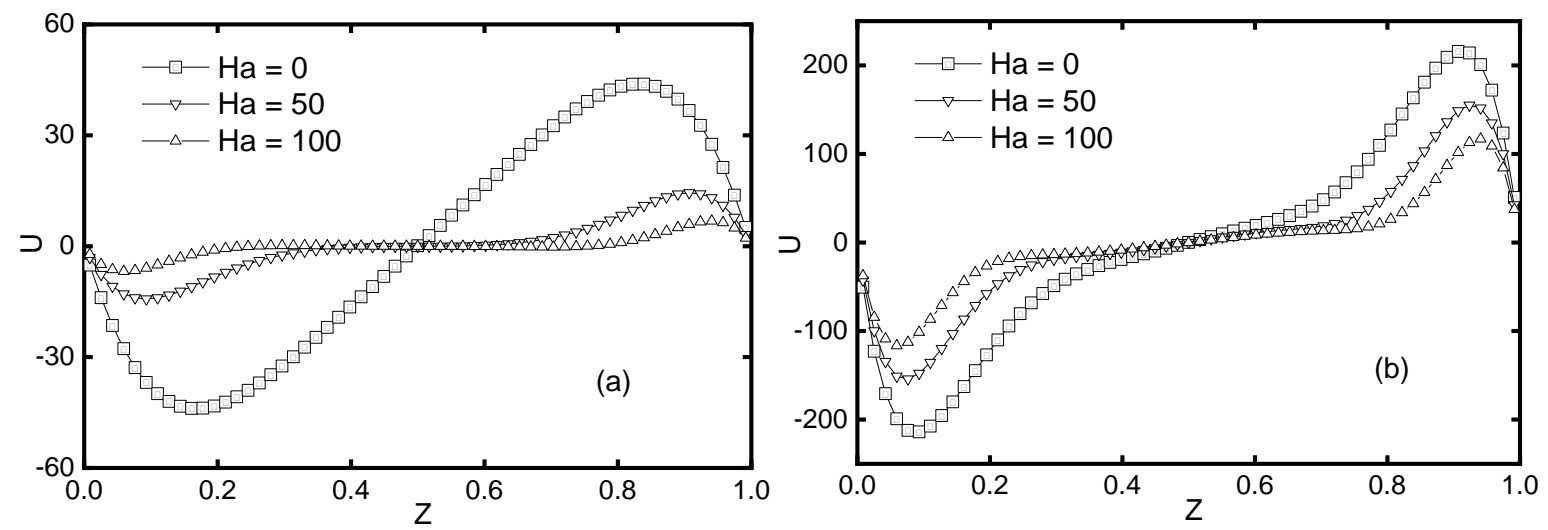

Figure 5. Variation of velocity $U$ at $Y=X=0.5$ and $\varphi=5 \%$ with Hartmann number for (a) $R a=10^{5}$, (b) $R a=10^{7}$
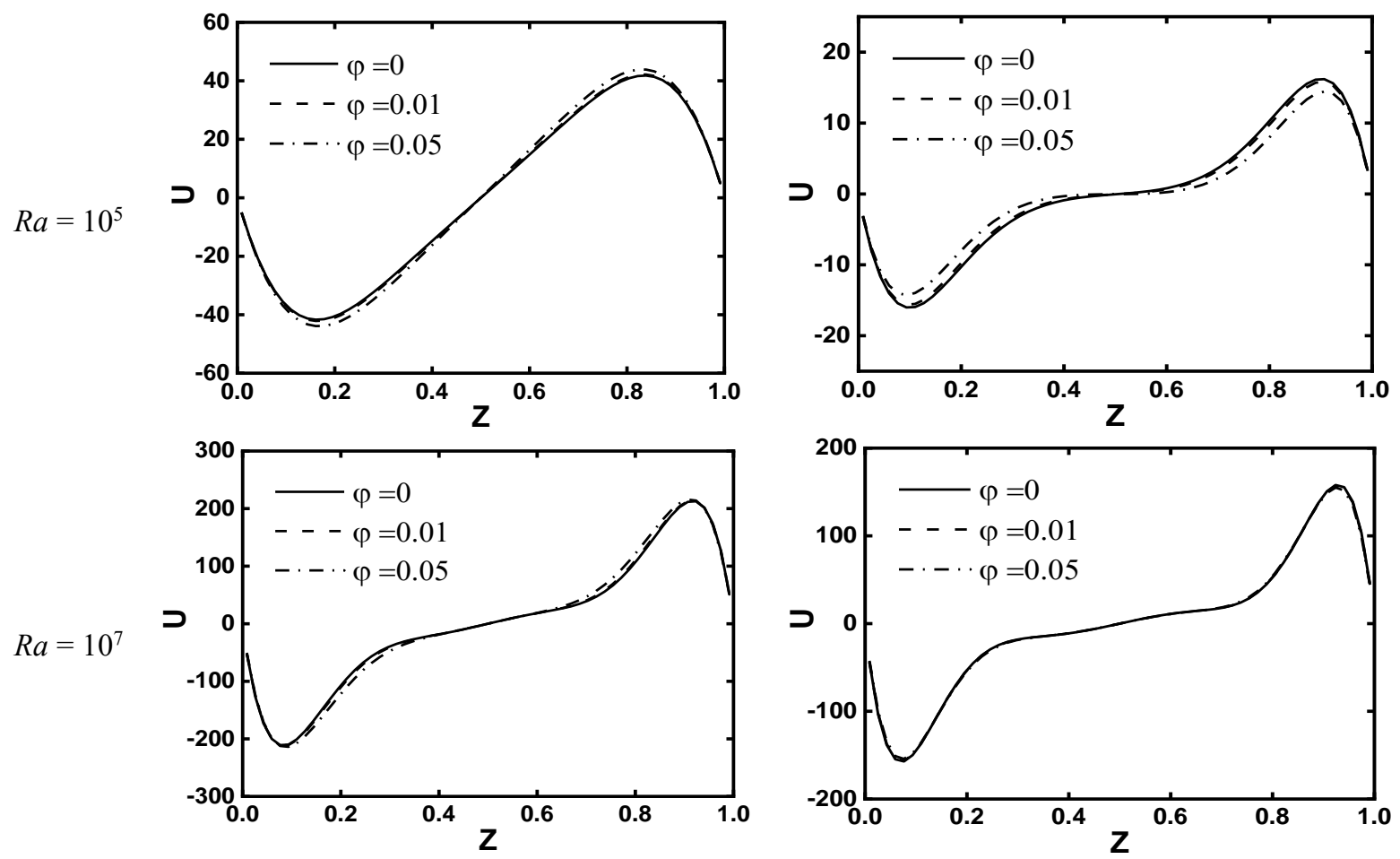

Figure 6. Variation of velocity $U$ at $X=Y=0.5$ as a function of $\varphi$ at different $R a$ and $H a$

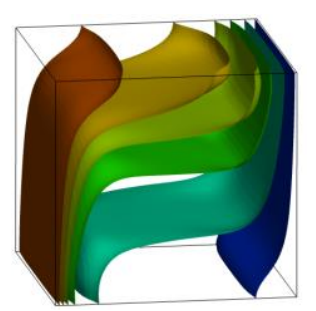

$H a=0$

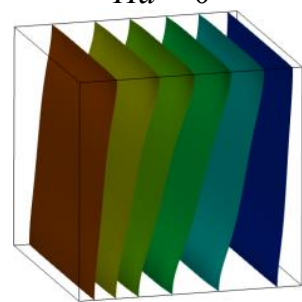

$H a=100$

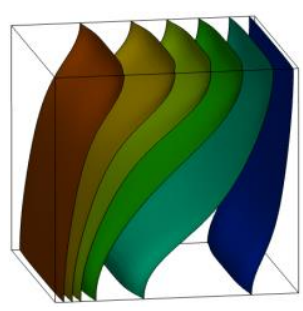

$\mathrm{Ha}=50$

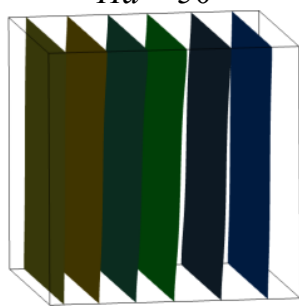

$H a=200$
Figure 7. Isosurfaces of temperature for $R a=10^{5}$ and $\varphi=5 \%$

Figure 6 displays the effect of the increase in nanoparticles on the flow field. At the Rayleigh number $10^{5}$ and with a relatively large Hartmann number $(H a=50)$, the effect of nanoparticles on the intensity of the circulating flow is more marked. Contrarily, at $R a=10^{7}$ and $H a=50$, the effect of the addition of nanoparticles on the intensity of the circulating flow is negligible.

Figure 7 shows the temperature isosurfaces for different Hartmann number values. In no the magnetic field $(H a=0)$, the layers are distributed in the middle in the horizontal direction. As the $H a$ increases, the stratification is straightened vertically, and the temperature field distribution is similar to that by conduction.

The variations of $N u_{\text {avg }}$ in Figure 8 show the effects of Hartmann number $(0<H a<200)$ at $\varphi=0.05$ for different values of $R a\left(10^{3} \ldots 10^{7}\right)$.

At Rayleigh number $R a=10^{3}$ where the heat transfer is dominated by conduction, $N u_{\text {avg }}$ remains constant whatever the Hartmann number. For $R a=10^{4}$, the $N u_{\text {avg }}$ remains unchanged beyond $H a=50$. On the other hand, if the Rayleigh number is high, the $N u_{\text {avg }}$ decreases for high Hartmann numbers because heat transfer is dominated by convection, and the application of a magnetic field on convection can cause significant changes in the structure of the flow. 


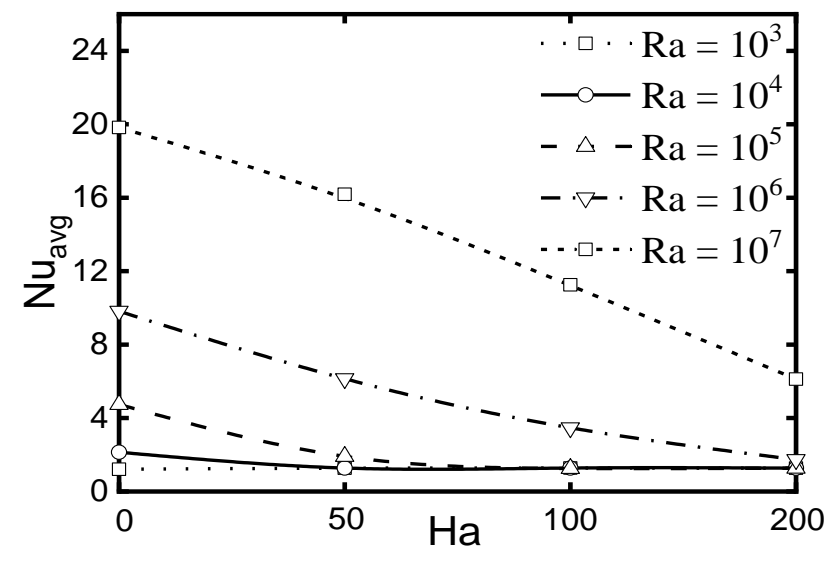

Figure 8. Variation of $N u_{a v g}$ as a function of $H a$ and $R a$, with $\varphi=5 \%$

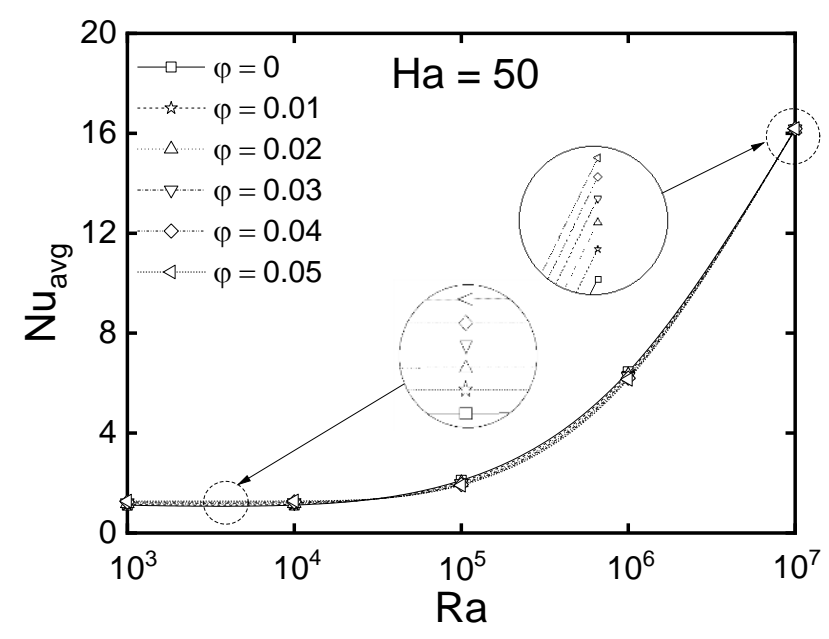

Figure 9. Variation of $N u_{\text {avg }}$ with Rayleigh number and nanoparticle volume fraction with $H a=50$

Figure 9 shows the variation of $N u_{a v g}$ under the influence of percentage of nanoparticles for a Rayleigh number varies from $10^{3}$ to $10^{7}$. When $R a$ is low, it is correct that since the flux is mainly conduction, the heat transfer remains unchanged.

For higher $R a$ values, the flow has become by convection and the rate of heat transfer is improved. Figure 9 also shows that, for all Rayleigh numbers, the $N u_{\text {avg }}$ increases with increasing nanoparticles volume fraction. This result is explained by the increased thermal conductivity of nanofluid.

\section{CONCLUSION}

In this study, we used a numerical approach to the finite volume method to solve conservation equations and the SIMPLEC algorithm to investigate the influence of the presence of a magnetic field in free convection in a cubic space full of nanofluids.

The results were presented for $\mathrm{Ra}\left(10^{3} \ldots 10^{7}\right), \mathrm{Ha}(0 \ldots 200)$ and $\varphi(0 \ldots 0.05)$ in form of isotherms, velocity profiles, streamlines, and average Nusselt number. The main conclusions that can be drawn are as follows.

- The increase in $R a$ intensifies the circulation of convective flows and leads to an acceleration of heat transfer by natural convection.

- At low value of Rayleigh number, where conduction is dominant, the $N u_{a v g}$ remains unchanged whatever the value of $H a$.

- In the case of strong magnetic fields, a $R a=10^{5}$, convection is completely replaced by conduction, and the role of nanoparticles in improving the average Nusselt number is negligible.

- For higher Rayleigh values, where the convective flow cycle is strengthened, the magnetic field will cause the heat transfer rate to decrease.

\section{REFERENCES}

[1] Choi, S.U.S., Eastman, J.A. (1995). Enhancing thermal conductivity of fluids with nanoparticles. Dev Appl Non Newtonian Flows, 66: 99-106.

[2] Yang, Y., Zhang, Z.G., Grulke, E.A., Anderson, W.B., $\mathrm{Wu}, \mathrm{G}$. (2005). Heat transfer properties of nanoparticlein-fluid dispersions (nanofluids) in laminar flow. International Journal of Heat and Mass Transfer, 48(6): 1107-1116.

https://doi.org/10.1016/j.ijheatmasstransfer.2004.09.038

[3] Khanafer, K., Vafai, K., Lightstone, M. (2003). Buoyancy-driven heat transfer enhancement in a twodimensional enclosure utilizing nanofluid. International Journal of Heat and Mass Transfer, 46(19): 3639-3653. https://doi.org/10.1016/S0017-9310(03)00156-X

[4] Abu-Nada, E., Oztop, H.F. (2009). Effects of inclination angle on natural convection in enclosures filled with $\mathrm{Cu}-$ water nanofluid. International Journal of Heat and Fluid Flow. 30(4): 669-678. https://doi.org/10.1016/j.ijheatfluidflow.2009.02.001

[5] Oztop, H.F., Abu-Nada, E. (2008). Numerical study of natural convection in partially heated rectangular enclosures filled with nanofluid. International Journal of Heat and Fluid Flow, 29(5): 1326-1336. https://doi.org/10.1016/j.ijheatfluidflow.2008.04.009

[6] Mohebbi, R., Izadi, M., Chamkha, A.J. (2017). Heat source location and natural convection in a $\mathrm{C}$-shaped enclosure saturated by a nanofluid. Physics of Fluids, 29(12): 122009. https://doi.org/10.1063/1.4993866

[7] Charafi, M.M., Bendaraa, A., Hasnaoui, A. (2018). Numerical modelling of natural convection in a square cavity: Effect of nanofluid volume fraction and inclination. MATEC Web Conf., 241: 01006. https://doi.org/10.1051/matecconf/201824101006

[8] Boudjeniba, B., Laouer, A., Laouar, S., Mezaache, E. (2019). Transition to chaotic natural convection of $\mathrm{Cu}$ water nanofluid in an inclined square enclosure. International Journal of Heat and Technology, 37(2): 413-422. https://doi.org/10.18280/ijht.370206

[9] Sheremet, M.A., Pop, I., Mahian, O. (2018). Natural convection in an inclined cavity with time-periodic temperature boundary conditions using nanofluids: Application in solar collectors. International Journal of Heat and Mass Transfer, 116: 751-761. https://doi.org/10.1016/j.ijheatmasstransfer.2017.09.070

[10] Boualit, A., Zeraibi, N., Chergui, T., Lebbi, M., Boutina, L., Laouar, S. (2017). Natural convection investigation in square cavity filled with nanofluid using dispersion model. International Journal of Hydrogen Energy, 42(13): 8611-8623. https://doi.org/10.1016/j.ijhydene.2016.07.132

[11] Albojamal, A., Vafai, K. (2017). Analysis of single phase, discrete and mixture models, in predicting nanofluid 
transport. International Journal of Heat and Mass Transfer, 114: 225-237. https://doi.org/10.1016/j.ijheatmasstransfer.2017.06.030

[12] Roy, N.C. (2018). Natural convection of nanofluids in a square enclosure with different shapes of inner geometry. Physics of Fluids, 30(11): 113605. https://doi.org/10.1063/1.5055663

[13] Joshi, S., Mahapatra, S., Pattamatta, A. (2017). Effect of particle shape and slip mechanism on buoyancy induced convective heat transport with nanofluids. Physics of Fluids, 29(12):

122001 https://doi.org/10.1063/1.4996824

[14] Ravnik, J., Skerget, L., Hribersek, M. (2010). Analysis of three-dimensional natural convection of nanofluids by BEM. Engineering Analysis with Boundary Elements, 34(12):

1018-1030. https://doi.org/10.1016/j.enganabound.2010.06.019

[15] El Moutaouakil, L., Boukendil, M., Zrikem, Z., Abdelbaki A. (2020). Natural convection and thermal radiation influence on nanofluids in a cubical cavity. International Journal of Heat and Technology, 38(1): 5968. https://doi.org/10.18280/ijht.380107

[16] Selimefendigil, F., Öztop, H.F. (2019). Conjugate mixed convection of nanofluid in a cubic enclosure separated with a conductive plate and having an inner rotating cylinder. International Journal of Heat Mass Transfer, 139: $1000-1017$ https://doi.org/10.1016/j.ijheatmasstransfer.2019.05.053

[17] Atashafrooz, M. (2018). Effects of Ag-water nanofluid on hydrodynamics and thermal behaviors of threedimensional separated step flow. Alexandria Engineering Journal, 57(4): 4277-4285. https://doi.org/10.1016/j.aej.2017.07.016

[18] Sajjadi, H., Delouei, A.A., Sheikholeslami, M., Atashafrooz, M., Succi, S. (2019). Simulation of three dimensional MHD natural convection using double MRT Lattice Boltzmann method. Physica A: Statistical Mechanics and its Applications, 515: 474-496. https://doi.org/10.1016/j.physa.2018.09.164

[19] Zhou, W., Yan, Y., Xie, Y., Liu, B. (2017). Three dimensional lattice Boltzmann simulation for mixed convection of nanofluids in the presence of magnetic field. International Communications in Heat and Mass Transfer, 80 :

$1-9$. http://doi.org/10.1016/j.icheatmasstransfer.2016.11.012

[20] Al-Sayegh, R. (2018). Influence of external magnetic field inclination on three dimensional buoyancy-driven convection in an open trapezoidal cavity filled with CNT-water nanofluid. International Journal of Mechanical Sciences, 148: 756-765. https://doi.org/10.1016/j.ijmecsci.2018.09.032

[21] Al-Rashed, A.A.A.A., Kalidasan, K., Kolsi, L., Aydi, A., Malekshah, E.H., Hussein, A.K., Rajesh Kanna, P. (2018). Three-dimensional investigation of the effects of external magnetic field inclination on laminar natural convection heat transfer in CNT-water nanofluid filled cavity. Journal of Molecular Liquids, 252: 454-468. https://doi.org/10.1016/j.molliq.2018.01.006
[22] Bejan, A. (2013). Convection Heat Transfer. John Wiley \& Sons, Inc., Hoboken, New Jersey, USA.

[23] Abu-Nada, E., Oztop, H. (2009). Effect of inclination angle on natural convection in enclosure filled with $\mathrm{Cu}$ water nanofluids. International Journal of Heat and Fluid Flow, 30(4): 669-678. https://doi.org/10.1016/j.ijheatfluidflow.2009.02.001

[24] Patankar, S.V. (1980). Numerical Heat Transfer and Fluid Flow. Hemisphere Publishing Corporation, Taylor and Francis Group, New York.

[25] Van Doormaal J.P., Raithby G.D. (1984). Enhancements of the SIMPLE method for predicting incompressible fluid flows. Numerical Heat Transfer, 7(2): 147-163. https://doi.org/10.1080/01495728408961817

\section{NOMENCLATURE}

$\mathrm{B}_{0} \quad$ magnetic field strength, $\mathrm{T}$

$C_{p} \quad$ specific heat, $\mathrm{J} \mathrm{kg}^{-1} \mathrm{~K}^{-1}$

g gravitational acceleration, $\mathrm{m} \cdot \mathrm{s}^{-2}$

$\mathrm{h} \quad$ local heat transfer coefficient, $\mathrm{W} \mathrm{m}^{-2} \mathrm{~K}^{-1}$

$\mathrm{H} \quad$ width of the enclosure, $\mathrm{m}$

$\mathrm{Ha} \quad$ Hartmann number

$\mathrm{k}$ thermal conductivity, $\mathrm{W} \mathrm{m} \mathrm{m}^{-1} \mathrm{~K}^{-1}$

$\mathrm{Nu} \quad$ Nusselt number

$\mathrm{P} \quad$ Pressure, $\mathrm{Pa}$

Pr Prandtl number

$\mathrm{T}$ dimensional temperature, ${ }^{\circ} \mathrm{C}$

$\mathrm{u}, \mathrm{v}, \mathrm{w}$ dimensional velocity components, $\mathrm{m} \mathrm{s}^{-1}$

$\mathrm{U}, \mathrm{V}$, dimensionless velocity components

$\mathrm{W}$

$\mathrm{x}, \mathrm{y}, \mathrm{z} \quad$ dimensional coordinates, $\mathrm{m}$

$\mathrm{X}, \mathrm{Y}, \mathrm{Z}$ dimensionless coordinates, $\mathrm{X}=$ $\mathrm{x} / \mathrm{H}, \mathrm{Y}=\mathrm{y} / \mathrm{H}, \mathrm{Z}=\mathrm{z} / \mathrm{H}$

\section{Greek symbols}

$\alpha \quad$ thermal diffusivity, $m^{2} s^{-1}$

$\beta \quad$ thermal expansion coefficient, $K^{-1}$

$\mu \quad$ dynamic viscosity, $P a$. $S$

$v \quad$ kinematic viscosity, $m^{2} s^{-1}$

$\theta$ dimensionless temperature, $\theta=$

$\left(\mathrm{T}-\mathrm{T}_{\mathrm{c}}\right) /\left(\mathrm{T}_{\mathrm{h}}-\mathrm{T}_{\mathrm{c}}\right)$

$\rho \quad$ density, $\mathrm{kg} \mathrm{m}^{-3}$

$\sigma \quad$ electrical conductivity, $\Omega^{-1} \mathrm{~m}^{-1}$

$\varphi \quad$ solid volume fraction

\section{Subscripts}

$\begin{array}{ll}\text { avg } & \text { average } \\ \mathrm{c} & \text { cold } \\ f & \text { base fluid } \\ \mathrm{h} & \text { hot } \\ n f & \text { nanofluid } \\ \mathrm{p} & \text { particle }\end{array}$

